\title{
IS FACEBOOK HARMFUL? EFFECTS OF INTENSE FACEBOOK USE ON UNIVERSITY STUDENTS' WORK
}

\author{
Valentina Iuliana MANEA ${ }^{1}$, Gabriel GORGHIU ${ }^{2}$, Costin PRIBEANU ${ }^{3}$ \\ ${ }^{1}$ Technical University of Civil Engineering, Bucharest, \\ ${ }^{2}$ Valahia University of Târgoviște, \\ ${ }^{3}$ Academy of Romanian Scientists, Bucharest, \\ ROMANIA, \\ E-mail: ${ }^{1}$ vmanea@yahoo.ro, ${ }^{2}$ ggorghiu@gmail.com, ${ }^{3}$ costin.pribeanu@gmail.com
}

\begin{abstract}
The advances in social media technology and mobile devices have an important impact on the educational process, in a general context in which the use of social networks have a great influence on many aspects of daily life. However, despite the great potential of social networks in the field of education, the possibilities of applying interactive methodologies that include social networking and turning the actual education in a more attractive format of learning is still in a beginner phase... In this respect, it is obvious that the education providers do not exploit enough such learning environments. However, the objective of this paper is to analyze the negative effects of Facebook use on university students' work. A summated scale for the Facebook intensity of use has been proposed, by integrating three variables: the number of Facebook friends, the number of daily logs, and the time spent daily. Three Facebook user profiles have been defined based on the intensity of use: low, moderate, and high Facebook intensity. The results show significant group differences which especially as regards the concentration in university and students' work.
\end{abstract}

Keywords: social networking websites; Facebook; problematic use; negative effects of social network; the intensity of Facebook use;

\section{INTRODUCTION}

Nowadays, social media technology and mobile devices could have a great potential in the educational process. Practically, the use of social networks in education represents a form of recognition of all the social changes induced by their presence in our daily lives.

At present, social networks should be considered an educational tool, due to the fact that most of them allow the creation of groups (e.g. class-group, group of certain groups), and in this way, the information is sent in an easy and fast way. Learning through the use of such networks represents an attractive educational alternative that reduces various restrictions: temporal, social, or spatial.

There are a series of advantages related to the use of social networks in education: considering the space in which the students are working, this has an intimate character and does not require formalization; the student can learn at his own pace; the own progress can be controlled quickly; the student benefits of fast and permanent feedback; the interaction with 
the teacher is free and unconstrained; there are no travel fees involved and the time allocated for virtual meetings can be flexible. More, in a virtual classroom, students of all ages can be brought together, having different backgrounds, and neglecting the distances.

In terms of disadvantages, it is important to mention: dependence, privacy concerns, possible exposure of personal data, cyberbullying, but also depression (Moreno, et al., 2011; Park et al., 2013). Pantic (2014) emphasized the negative correlations between the frequent use of social networks and well-being or mental health.

Overall, on the one hand, both educators and students have to take advantage from the new opportunities created by the social networking websites (Ellison et al., 2007; Greenhow \& Levin, 2016; Pribeanu et al., 2018) and to effectively adapt to social learning (Brown \& Adler, 2008; Manca \& Ranieri, 2016). On the other hand, too much time spent on social media websites is affecting the students' concentration in the university activities, and it may even lead to adverse effects on their lives (LaRose et al, 2010; Balog et al., 2013; Orosz et al., 2015; Gorghiu et al., 2016).

However, social networks offer to students the feeling of belonging to a community, but also the opportunity to explore their own identity.

\section{RELATED WORK}

There is no clear boundary between the use and abuse of social media sites. Waycott et al. (2013) expressed several concerns related to the positive effects of using social networks in higher education, but there are also authors who insisted on its negative effects, mainly on students' academic performance (Kirschner, \& Karpinski, 2010; Paul et al., 2012). In addition, there were introduced concerns related to the plagiarism situations or possible rejection of students' various views (Yu et al., 2010; Waycott et al., 2013).

If we limit the discussion just to Facebook, related works illustrate a diversity of terms related to on-line activities: excessive, problematic, addictive, unregulated (Young, \& Rogers, 1998; Caplan, 2002; LaRose et al., 2010; Orosz et al., 2015). The study of LaRose et al. (2010) analyzed the Facebook use focusing on different types of Facebook activities and proposed a model of habitual Internet activities rooted in the social cognitive theory and media consumption theory. They argued to make a distinction between different habitual activities when analyzing the negative life consequences.

Ellison et al. (2007) developed a composite measure for the Facebook intensity that combined two characteristics of use (number of Facebook friends and minutes spent daily) with six attitudinal items. Although the scale is not unidimensional, it has been widely used in social networking websites research.

They found that Facebook intensity predicts the level of three forms of social capital. They also found a relationship between Facebook usage and psychological wellbeing, especially for users having low self-esteem and life satisfaction.

Orosz et al. (2015) proposed a Multidimensional Facebook Intensity Scale having four dimensions: persistence, boredom, overuse, and self-expression. On the one hand, the scale enables a more detailed analysis of problematic and non-problematic Facebook use. On another hand, it enables the prediction of frequent Facebook-related behaviors.

Munkaila \& Iddrisu (2015) specified that the extensive use of social networks by students can have a negative impact on their social interaction, and more, can lead to depression, sleep disorders and dependence. 
In this sense, Gorghiu et al. (2016) analyzed the relationship between Facebook dependence and its negative effects on students' work on three groups according to the number of Facebook friends. The comparison between groups showed that students having larger networks also log on Facebook more often, spend more time on Facebook daily, have a higher level of dependence, and their university work is more affected.

\section{METHOD AND SAMPLE}

The goal of this study is to find out the extent to which an intense Facebook use has negative effects on the students' work. The Facebook intensity (FB-Int) is measured with a summated scale that integrates three variables: number of Facebook friends, logging behavior, and minutes spent daily on Facebook. The measure differs from the Facebook intensity measure defined by Ellisson et al. (2007) in two respects:

- it does not include attitudinal items since those are related to various aspects such as emotional affect or dependence.

- it includes the number of logs/day (daily frequency of use).

The frequency of use has been measured with the help of two variables: number of days/week and number of logs/day $(1=$ once, $2=$ twice, $3=$ three times and more, $4=$ continuous $\log$ ). The number of Facebook friends and the minutes spent daily on Facebook have been scaled on a 6-points scale, as shown in Table 1.

Table 1. Variable scaling

\begin{tabular}{|c|c|c|}
\hline Value & FB friends & Minutes / Day \\
\hline 1 & $1-300$ & $0-15$ \\
\hline 2 & $301-600$ & $16-30$ \\
\hline 3 & $601-1000$ & $31-60$ \\
\hline 4 & $1001-1500$ & $61-90$ \\
\hline 5 & $1501-2500$ & $91-120$ \\
\hline 6 & $>2500$ & $>120$ \\
\hline
\end{tabular}

The method is based on group comparison. Three groups have been defined based on the Facebook intensity: 3-6, 7-10, and 10-16. Those groups correspond to the low, moderate, and high intensity of use.

The sample consists of 182 students (127 males and 55 females) from Technical University of Civil Engineering in Bucharest. The data has been collected in May 2019. The age of participants ranges between 18 and 34 years old $(\mathrm{M}=20.36, \mathrm{SD}=2.00)$.

First, students have been asked to answer questions related to the characteristics of use: number of Facebook friends, frequency, and duration of use. Then, students have been asked to rate several items on a 7-points Likert scale. The items related to the negative effects of Facebook use are presented in Table 2.

Table 2. Items measuring the negative effects of Facebook

\begin{tabular}{|c|l|}
\hline Item & \multicolumn{1}{|c|}{ Statement } \\
\hline ANC1 & My academic performance suffers because of Facebook \\
\hline ANC2 & My concentration at university suffers because I am on Facebook \\
\hline ANC3 & I often neglect my university work because of Facebook \\
\hline
\end{tabular}




\section{RESULTS}

The number of Facebook friends ranges between 6 and 5781 with a mean of 1173.13 $(\mathrm{SD}=1113.12)$. The mean number of days/week is $5.54(\mathrm{SD}=2.10)$, the mean number of logs/day is 2.72 ( $\mathrm{SD}=0.87)$, and the time spent in minutes/day is on average 60.85 $(\mathrm{SD}=68.69)$, with a minimum of 3 and a maximum of 400 minutes. As it could be noticed, students have large Facebook networks and spend a lot of time daily.

The mean values for the characteristics of Facebook usage in each group are presented in Table 3. While the number of students in the first and third groups is almost equal, the second group is the largest, showing that almost half of the students (48.43\%) are using Facebook moderately.

Table 3. Characteristics of Facebook use

\begin{tabular}{|l|c|c|c|c|c|}
\hline \multicolumn{1}{|c|}{ FB-Int } & $\mathrm{N}$ & FBf & DaysWeek & LogDay & MinDay \\
\hline Low (3-6) & 46 & 489.30 & 4.39 & 1.80 & 15.74 \\
\hline Moderate (7-10) & 88 & 1076.57 & 5.69 & 2.86 & 50.69 \\
\hline High (11-16) & 48 & 2005.50 & 6.35 & 3.35 & 122.71 \\
\hline
\end{tabular}

As it could be noticed, the higher is the intensity of Facebook use, the larger are the network size, frequency, and duration of use. A one-way ANOVA $(2,179,181)$ showed that differences are statistically significant for all variables at $\mathrm{p}=0.000$ level.

The descriptives for those three items measuring the negative effects of Facebook on the university work of students are presented in Table 3. As it could be noticed, the negative effects are low to moderate.

Table 4. Descriptives for ANC items $(\mathrm{N}=182)$

\begin{tabular}{|l|c|c|c|c|}
\hline Item & Min & Max & Mean & SD \\
\hline ANC1 & 1 & 7 & 2.82 & 1.81 \\
\hline ANC2 & 1 & 7 & 2.75 & 1.75 \\
\hline ANC3 & 1 & 7 & 2.64 & 1.77 \\
\hline
\end{tabular}

The average of those three items is $2.73(\mathrm{SD}=1.63)$. An analysis of frequency for the mean value shows that for 133 students $(73.62 \%)$ is below 4 (neutral value, on a 7-point Likert scale), for 12 students is 4 (moderate negative effects), for 31 students is between 4 and 6 (high negative effects). Only 6 students reported a mean value over 6 , which means very high negative effects. Overall, for 145 students $(79.67 \%)$ the negative effects are low and moderate and for 37 students $(20.33 \%)$. the negative effects are high and very high.

The mean value of items measuring the negative effects of Facebook use for each group is presented in Table 5.

Table 5. Negative effects of Facebook by the intensity of use

\begin{tabular}{|l|c|c|c|c|}
\hline \multicolumn{1}{|c|}{ FB-Int } & $\mathrm{N}$ & ANC1 & ANC2 & ANC3 \\
\hline Low (3-6) & 46 & 2.41 & 2.17 & 1.96 \\
\hline Moderate (7-10) & 88 & 2.81 & 2.82 & 2.72 \\
\hline High (11-16) & 48 & 3.23 & 3.17 & 3.15 \\
\hline \multicolumn{1}{|c|}{ Total } & 182 & 2.82 & 2.75 & 2.64 \\
\hline
\end{tabular}

For each group, there is a positive correlation between Facebook intensity and the negative effects on students' work. For the last two items, the differences are larger between 
the first and the second group showing that even moderate Facebook use is affecting the concentration at university and the university work.

A one-way ANOVA $(2,179,181)$ showed that differences are statistically significant for all items: ANC1 $(\mathrm{F}=2.437, \mathrm{p}=0.090)$, ANC2 ( $\mathrm{F}=4.036, \mathrm{p}=0.019)$, and ANC3 $(\mathrm{F}=5.747, \mathrm{p}=0.004)$.

\section{DISCUSSION}

The study contributes to the analysis of the negative effects of Facebook on university students' work with an approach based on group comparison. A summated scale for the Facebook intensity of use has been proposed, by integrating three variables: the number of Facebook friends, the number of daily logs, and the time spent daily. Three Facebook user profiles have been defined based on the intensity of use: low, moderate, and high Facebook intensity.

The results confirm the findings of a previous study on the negative effects of excessive Facebook use on the Romanian university students' work (Gorghiu et al., 2016). For the whole sample, the items measuring the negative effects have an average magnitude below 3 on a 7-points Likert scale, which means a low to moderate negative effect of the Facebook intensity on the university work.

One of the main concerns remains the important amount of time which is spent by the students on surfing the Facebook. In this respect, it is necessary to separate the time dedicated for academic purposes, in opposition to that time in which the students are immersed in non-academic activities - the excessive use is materialized in spending time on looking at friends' images and commenting them, watching videos, posting or discussing.

As mentioned above, a moderate usage of Facebook has negative impact on student's concentration and work. This comes in the same line described by Kirschner \& Karpinski (2010), considering students' over-involvement or their obsession about the social networks, having major negative impact on their academic performance.

\section{CONCLUSIONS}

As an answer to the main question of this work ("Is Facebook harmful?"), it is clear that an excessive use of it could be really dangerous for students. Even though Facebook is attracting the interest of the educational actors now - many university students being declared themselves as big fans -, in some cases they lost their concentration and working energy for academic purposes. Without saying that the university students are possible "Facebook victims", it is obvious that their academic performance is negatively influenced by the excessive use of this social media site.

Of course, there are various possibilities to use social media in academic activities. Beyond that, it is extremely important for teachers, how to maximize its advantages, and minimize its negative effects (Gorghiu et al., 2016).

There are several limitations to this study. An inherent limitation is a fact that the data is based on self-reporting and issues related to dependence and negative effects on university work might be underestimated. Another limitation is related to the sample size and to the fact that it includes students from only one university. Students' perceptions of Facebook use might differ from generation to generation as well as from one university to another. 


\section{REFRENCES}

[1] Balog, A., Pribeanu, C., Lamanauskas, V., \& Slekiene, V. (2013) A multidimensional model for the exploration of negative effects of social networking websites as perceived by students. Journal of Baltic Science Education, 12(3), 378-388.

[2] Caplan, S.E. (2002). Problematic Internet use and psychosocial well-being: Development of a theory-based cognitive-behavioral measurement instrument. Computers in Human Behavior, 18, 553-575.

[3] Ellison, N.B., Steinfield, C., \& Lampe, C. (2007). The benefits of Facebook "friends:" Social capital and college students' use of online social network sites. Journal of Computer-Mediated Communication, 12(4), 1143-1168.

[4] Gorghiu, G., Pribeanu, C., \& Lamanauskas, V. (2016). On the Facebook Dependence and Its Negative Effects on University Students' Work: A Multi-Group Analysis. Problems of Education in the 21st Century, 73, 62-74.

[5] Greenhow, C., \& Lewin, C. (2016). Social media and education: Reconceptualizing the boundaries of formal and informal learning. Learning, Media and Technology, 41(1), 6-30.

[6] Kirschner, P.A., \& Karpinski, A.C. (2010). Facebook and academic performance. Computers in Human Behavior, 26(6),1237-1245.

[7] LaRose, R., Kim, J. \& Peng, W. (2010). Social networking: Addictive, compulsive, problematic, or just another media habit? In Z. Papacharissi (Ed.), A networked self: Identity, community, and culture on social network sites. New York, NY: Taylor \& Francis.

[8] Manca, S., \& Ranieri, M. (2016). Is Facebook still a suitable technology-enhanced learning environment? An updated critical review of the literature from 2012 to 2015. Journal of Computer Assisted Learning, 32(6), 503-528.

[9] Moreno, M.A., Jelenchick, L.A., Egan, K.G., Cox, E., Young, H., Gannon, K., \& Becker, T. (2011). Feeling bad on Facebook: depression disclosures by college students on a social networking site. Depress Anxiety, 28(6), 447-455.

[10] Munkaila, A., \& Iddrisu, A. (2015). The impact of social network sites on the academic performance of students in the Polytechnics of Ghana. International Journal of Economics, Commerce and Management, 3(11), 1021-1035.

[11] Orosz, G., Toth-Kiraly, I., \& Bothe, B. (2015) Four facets of Facebook intensity - the development of multidimensional Facebook intensity scale. Personality and Individual Differences, http://dx.doi.org/10.1016/j.paid.2015.11.03.

[12] Pantic, I. (2014). Online social networking and mental health. Cyberpsychology, behavior and social networking, 17(10), 652-657.

[13] Park, S., Lee, S.W., Kwak, J., Cha, M., \& Jeong, B. (2013). Activities on Facebook reveal the depressive state of users. Journal of Medical Internet Research, 15(10), e217.

[14] Paul, J., Baker, H., \& Cochran, J. (2012). Effect of online social networking on student academic performance. Computers in Human Behavior, 28(6), 2117-2127.

[15] Pribeanu, C., Iordache, D.D., \& Balog, A. (2018). Educational Opportunities Provided by the Social Networking Sites: A Multidimensional Model. The International Scientific Conference eLearning and Software for Education, Vol. 4, Bucharest, Romania, 216-223.

[16] Waycott, J., Sheard, J., Thompson, C., \& Clerehan, R. (2013). Making students work visible on the social web: A blessing or a curse? Computers \& Education, 68, 86-95.

[17] Young, K. S., \& Rogers, R. C. (1998). The relationship between depression and Internet addiction. Cyberpsychology and Behavior, 1, 25-36.

[18] Yu, A., Tian, S., Vogel, D., \& Kwok, R. (2010). Can learning be virtually boosted? An investigation of online social networking impacts. Computers \& Education, 55(4), 1494-1503. 